\title{
Articulatory analysis of transparent vowel /i:/ in harmonic and antiharmonic Hungarian stems: Is there a difference?
}

\author{
Alexandra Markó ${ }^{1,2}$, Márton Bartók ${ }^{1,2}$, Tamás Gábor Csapó ${ }^{2,3}$, Tekla Etelka Gráczi ${ }^{2,4}$, \\ Andrea Deme ${ }^{1,2}$ \\ ${ }^{1}$ Eötvös Loránd University, Budapest, Hungary \\ ${ }^{2}$ MTA-ELTE “Lendület” Lingual Articulation Research Group, Budapest, Hungary \\ ${ }^{3}$ Budapest University of Technology and Economics, Budapest, Hungary \\ ${ }^{4}$ Research Institute for Linguistics HAS, Budapest, Hungary \\ marko.alexandra@btk.elte.hu, bartokmarton@gmail.com, csapot@tmit.bme.hu, \\ graczi.tekla.etelka@nytud.mta.hu, deme.andrea@btk.elte.hu
}

\begin{abstract}
The aim of our study is to analyse the articulatory characteristics of /i:/ occurring in Hungarian monosyllabic harmonic and antiharmonic stems. In their frequently cited work, based on 3 speakers' data, Beňuš and Gafos (2007) [1] claimed that the tongue position in transparent vowels of antiharmonic Hungarian stems is less advanced than that of the phonemically identical vowels in harmonic stems. In their study, the authors compared different harmonic and antiharmonic stems (even if the consonantal context was more or less controlled).

In the present study, we analysed two homophonous pairs of words /si:v/ and /nirr/, which are antiharmonic in their verbal usage, but are harmonic as nouns. The words were produced by 4 speakers both (i) in isolation and (ii) in sentence-initial position, where they were followed by front and back vowels, in a well-controlled manner. The experiment was carried out using electromagnetic articulography. We compared the sequence of the horizontal position of four receiver coils (ttip, tbl, tbo1, tbo2) across the conditions with Generalized Additive Models. The results showed that the horizontal positions of the receivers did not vary as a function of the harmonicity of the stem in either the isolated or the coarticulated condition.

Index Terms: antiharmonic stem, harmonic stem, transparent vowel, Hungarian, electromagnetic articulography
\end{abstract}

\section{Introduction}

Backness harmony in Hungarian is a highly productive process, and due to the exceptional behavior of the so-called neutral or transparent vowels, it has been analysed extensively in the phonological literature [2]. (Although Hungarian also shows rounding harmony, this pattern is less complex, and irrelevant with respect to the present study.)

Hungarian vowel harmony is stem-controlled, and operates in the left-to-right direction. Regarding the backness harmony patterns, this means that the backness of the stem's final vowel assigns the backness of the suffix vowel. Most of the suffixes show front-back alternation in Hungarian, and suffix vowels receive their $[ \pm$ back $]$ quality from the $[ \pm$ back $]$ quality of the adjacent stem-final vowel [3].

In the phonological domain of the Hungarian vowel system harmonic and neutral vowels can be differentiated. Harmonic vowels can be classified as front, such as [y y: $\varnothing$ ø:], and back, as [ $u$ u: $\left.\begin{array}{llll} & \text { o: } & p & a:\end{array}\right]$. In the case of alternating suffixes and harmonic stem final vowels, backness harmony governs the quality of the suffix, without exception, e.g., ablak-ban /pblpkbpn/ 'window-LOC', üst-ben/yftben/ 'cauldron- LOC'.

Neutral vowels are phonetically front unrounded [i i: e: $\varepsilon$ ], but from the phonological aspect they are neither front nor back, as they are transparent with respect to harmony, i.e., "they let harmony pass through them as if they were not there at all" [3, p. 172]. If the stem final vowel is neutral/transparent, the backness of the suffix vowel is governed by the last harmonic vowel within the stem, e.g., kastély-ban /kpjte:jbon/ 'castleLOC'.

The question thus arises whether back or front suffix is selected if the stem is monosyllabic, and its vowel is neutral/transparent. In Hungarian, both patterns can be observed. We can find stems selecting front suffixes (harmonic stems), where the phonetically front unrounded vowels [i i: e: $\varepsilon$ ] behave as phonologically front ones, e.g., víz-ben /vi:zben/ 'water-LOC', kéz-ben /ke:zben/ 'hand-LOC'. However, other monosyllabic stems with these vowels are followed by back suffixes (antiharmonic stems), e.g., sír-ban / Jirrbpn/ 'tombLOC', cél-ban /tse:lbpn/ 'target-LOC'.

While in the phonological literature we find a wealth of papers on the patterns of Hungarian backness harmony, the number of the experimental studies on this topic is rather low. In their frequently cited study, Beňuš and Gafos [1] presented two articulatory analyses of Hungarian transparent vowels. In their research, they used electromagnetic midsagittal articulometry, which is suitable for imaging a limited number of tongue flesh-points, and ultrasound tongue imaging, which gives information of the midsagittal view of the global tongue surface. Three young speakers of Budapest dialect participated in the study, two females and one male. In the electromagnetic articulographic experiment three receiver coils were applied: for two speakers two on the tongue body (TB1, TB2) and one on the tongue dorsum (TD); for one speaker one on the tongue tip (TT), one on the tongue body and one on the tongue dorsum. The authors determined the most front position of the TB, TD receiver coils during the transparent vowel, and analysed these data as a function of the harmonic type (front, i.e. harmonic or back, i.e. antiharmonic) of the target words. Ultrasound data were also collected from one speaker. The target words (see below) were embedded in a carrier sentence twice, in different structural positions which evoked various prosodic realizations. 
Four repetitions were recorded from both (trisyllabic and monosyllabic) sets of stimuli.

In the first experiment, the authors analysed the tongue body position during transparent vowels both in front and back harmony contexts, e.g., bili-vel 'pot-INSTR' /bilivel/ and buli-val /bulivbl/ 'party-INSTR', where transparent vowels occurred in disyllabic stems and were followed by a monosyllabic suffix. The target words were embedded in a carrier sentence. Since in this experiment the target vowels were surrounded by either front or back vowels, it was rather expectable that the environment elicited more retracted tongue position in transparent vowels surrounded by back vowels compared to those counterparts which were surrounded by front vowels. Accordingly, the authors observed more retracted tongue body position of transparent vowels among back vowels than among front ones.

In the second experiment presented by Beňuš and Gafos [1], transparent vowels in the front- (harmonic) and back-selecting (antiharmonic) stems were not adjacent to any other vowels, more precisely the target words were monosyllabic, but they were also embedded in a carrier sentence. As the authors mentioned, they tried to compile a set of stimuli in which the front- and back-selecting stems were comparable as much as it was possible. Four examples of their eight pairs of stimuli are the following ( $\mathrm{B}$ and $\mathrm{F}$ indicate back-selecting and frontselecting stems, respectively): $v i v_{\mathrm{B}} / \mathrm{vi} \mathrm{iv} /$ 'fence' vs. $i v_{\mathrm{F}} / \mathrm{i}: \mathrm{v} /$ 'bow'; vig $/$ /vi:g/ 'cheerful' vs. míg? /mi:g/ 'while'; sip $p_{\mathrm{B}} / \mathrm{ji}$ /p/ 'whistle' vs. cim / tsi:m/ 'address'; nyit $/$ /nit/ 'open' vs. hisz /his/ 'believe'. It can be noticed that not all members of the pairs agreed in their syllable structures (CVC vs. VC, see viv and $i v)$. Moreover, it should be noted that the harmonic behavior of mig cannot be judged, since it cannot be combined with any suffix. Finally, some of the surrounding consonants differed in their place of articulation (postalveolar [S] vs. alveolar [ts]; palatal [n] vs. laryngeal $[\mathrm{h}]$ ), and these differences might have an effect on the data. In the case of back-selecting sip, the initial consonant's place of articulation is more retracted than its counterpart in the front-selecting cim. Similarly, in the case of nyit, there is a palatal obstruction in the articulation of the word-initial consonant, while there is no oral constriction at the beginning of the front-selecting member (hisz) of this pair of stimuli.

The authors found that also in the second set of stimuli, the tongue position is more retracted in the case of back-selecting (antiharmonic) stems than in their front-selecting (harmonic) counterparts. Based on these data, they concluded that "because monosyllabic stimuli were presented in isolation (no suffixes), the observed sub-phonemic differences cannot be attributed to contextual coarticulation" $[1$, p. 286].

The above cited proposition is well-known in the literature, and serves as a basis for further statements and theoretical assumptions. However, as we have seen above, in the case of the set of trisyllabic stimuli, the results could be explained simply by the contextual V-to-V coarticulation, and in the case of the set of monosyllabic stimuli, the suitability of some of the pairs of the target words appeared to be questionable. On this basis, in the present study, homophonous front-selecting (harmonic) and back-selecting (antiharmonic) stems were chosen, and electromagnetic articulographic experiments were conducted in order to test the following hypotheses.

First, we hypothesized that articulation of /i:/ vowels pronounced in isolated (no suffix) monosyllabic homophonous front-selecting (harmonic) and back-selecting (antiharmonic) stems show different horizontal tongue positions. In back- selecting stems, the tongue was supposed to be positioned more retracted during the articulation of/i:/ than in the front-selecting stems.

Our second hypothesis was that in sentence-initial position, where the target words are followed by (i) front or (ii) back vowels, the horizontal tongue position of /i:/ vowels shows differences as a function of the stem's harmonic behavior due to the coarticulatory (V-to-V) effect of the following vowels.

\section{Method}

\subsection{Stimuli, data recording, and participants}

In the present study, two pairs of monosyllabic homophonous front-selecting (harmonic) and back-selecting (antiharmonic) stems were analysed, see Table 1.

Table 1: Target words.

\begin{tabular}{cccc}
\hline $\begin{array}{c}\text { Target } \\
\text { word }\end{array}$ & $\begin{array}{c}\text { Phonological } \\
\text { structure }\end{array}$ & $\begin{array}{c}\text { Harmonic } \\
\text { type }\end{array}$ & Meaning \\
\hline nyír & $/$ ji:r/ & $\begin{array}{c}\text { front-selecting } \\
\text { back-selecting } \\
\text { front-selecting } \\
\text { back-selecting }\end{array}$ & $\begin{array}{c}\text { 'birch' 'trim' } \\
\text { 'heart' }\end{array}$ \\
\hline
\end{tabular}

The target words were analysed both in isolation (isolation setup), where neither a suffix nor a carrier sentence were applied, and in carrier sentences (sentence setup), where the target word was positioned at the beginning of the sentence, and was followed by a word containing (i) only front vowels (éppen /e:p:en/ 'though') or (ii) only back vowels (ugyan /ujpn/ 'though'), see Table 2. This way we could control both the possible effects of the context and the stress patterns of the target words. (Neither of them could have been guaranteed in the case of sentence-medial occurrences due to the prosodic characteristics of Hungarian.)

Table 2: Target words in carrier sentences (sentence setup).

\begin{tabular}{|c|c|c|c|}
\hline $\begin{array}{c}\text { Target } \\
\text { word }\end{array}$ & $\begin{array}{c}\text { Harmonic } \\
\text { type }\end{array}$ & Context & Sentence \\
\hline \multirow{4}{*}{ nyír } & \multirow{2}{*}{ front-sel. } & éppen & Nyír éppen ez a csemete... \\
\hline & & ugyan & Nyír ugyan ez a csemete... \\
\hline & \multirow{2}{*}{ back-sel. } & éppen & Nyír éppen a fünyíró... \\
\hline & & ugyan & Nyír ugyan a fünyíró... \\
\hline \multirow{3}{*}{ szív } & \multirow{2}{*}{ front-sel. } & éppen & Szív éppen... \\
\hline & & ugyan & Szív ugyan... \\
\hline & back-sel. & éppen & Szív éppen a porszívó... \\
\hline
\end{tabular}

In isolation setup, nine pairs of homophonous monosyllabic words were used as fillers: $f a l_{\mathrm{B}}$ 'wall' and 'devour', nyom $_{\mathrm{B}}$ 'trace' and 'push', nöF 'woman' and 'grow', nyúl $l_{\mathrm{B}}$ 'rabbit' and 'reach', sir ' 'tomb' and 'cry', füzF 'willow' and 'stitch', $f e j_{\mathrm{F}}$ 'head' and 'squeeze', vár 'castle' and 'wait', fél $l_{\mathrm{F}}$ 'half' and 'fear'. Pictures were applied in order to make the meaning of the target words unambiguous for the speakers.

All stimuli were recorded in five repetitions. Three random orders of words in isolation and three random orders of sentences were compiled, and then blocked and mixed as follows: 22 words, 8 sentences, 22 words, 8 sentences and so 
on (five repetitions). The stimuli were presented on a computer screen.

Data recordings were carried out in a sound treated room using a Carstens EMA AG501 system. We recorded the tongue movements at tongue tip (ttip), tongue blade (tbl), and two points on the tongue dorsum (tbo1, tbo2). In parallel, audio signal was recorded using a head-mounted omnidirectional condenser microphone, with the software provided by Carstens, in wav files.

4 healthy native speakers of Hungarian participated in the study, all females, aged between 23 and 26 years.

\subsection{Data processing and analyses}

Head movement and bite plane corrections were done by the Carstens software, while further post-processing (3D-2D conversion) was carried out by the custom made converter of the IfL Phonetik, University of Cologne. Segmental labelling of the audio signal was carried out semi-automatically using the BAS web services G2P [4] and MAUS [5], and corrected manually in Praat [6].

The horizontal $(x)$ position of the four tongue receiver coils (ttip, tbl, tbo1, tbo2) were measured at the temporal midpoint of the target vowel, and compared as a function of the target word's harmonic type (front-selecting vs. back-selecting) in both setups. In order to get compatible data across speakers, the minimum and maximum of $x$ values were obtained for each speaker, based on [7]. For a given speaker, the minimum $x$ value was the extreme case of /u:/ from the filler word nyúl (the most retracted tongue position for $/ \mathrm{u}: /)$ and the maximum $x$ value was the extreme case of /i:/ from the filler word sir (the most fronted tongue position for /i:/). Next, absolute $x$ values were converted to percentage-point values relative to the minimum and maximum $x$ values. This means that the higher number (percentage) represents a more fronted receiver coil position. Since sir in both meanings evoke back suffixes, in accordance with our hypothesis we expected that in the analysed frontselecting stems the relative horizontal position of the receiver coils would exceed $100 \%$, while back-selecting stems would show values around $100 \%$.

In the isolation setup, 320 data points $(2$ target words $\times 2$ harmonic types $\times 5$ repetitions $\times 4$ receiver coils $\times 4$ speakers) were analysed, while in the sentence-initial setup, 640 (2 target words $\times 2$ harmonic types $\times 2$ contexts $\times 5$ repetitions $\times 4$ receiver coils $\times 4$ speakers). The data were analyzed by Generalized Additive Models (GAMs) in R [8] including byspeaker non-linear random effects, fitted using the package mgcv [9] to assess how the sequence of the normalised horizontal positions of the coils varied as a function of harmonic type (isolated setup) or the interaction between harmonic type and context (sentence setup). We also fitted separate models which also included the interaction of target word with the above factors. Akaike information criterion (AIC [10]) scores of these GAMs were compared to AIC scores of models not including by-condition smooths (using the compareML function in the itsadug package [11]), to assess model fits. GAMs not including the effect of target word were visualised using the package tidyMV [12].

\section{Results}

\subsection{Words in isolation (isolation setup)}

In general, we can observe differences between the two target words, nyir /nir/ and sziv/siv/, in both the front-selecting and the back-selecting harmonic types with respect to the horizontal position of the tongue (Fig.1). These differences were presumably due to the different consonantal contexts: in the case of nyir the surrounding palatal $\mathrm{C}_{1}$ and alveolar $\mathrm{C}_{2}$ elicit more retracted tongue position in the vowel than in the case of sziv, where /i:/ is adjacent to alveolar $\mathrm{C}_{1}$ and labiodental $\mathrm{C}_{2}$.

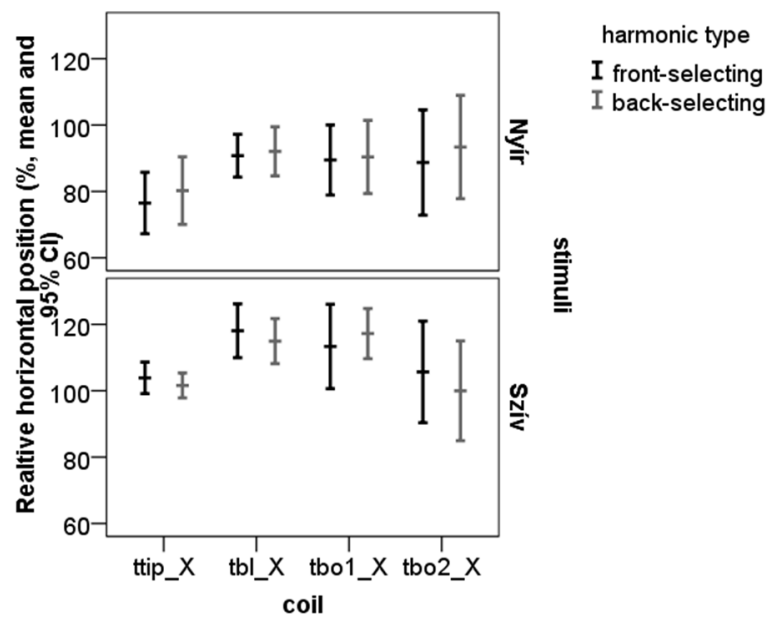

Figure 1: Relative horizontal coil positions (mean and 95\% CI) as a function of target word and harmonic type.

The horizontal position of the receiver coils did not differ as a function of the harmonic type (Fig.2). The model not including by-condition smooths had a lower AIC than the model containing those, both for the model not containing (AIC difference $=12.515)$ and containing the additional interaction with target word (AIC difference $=19.462)$.

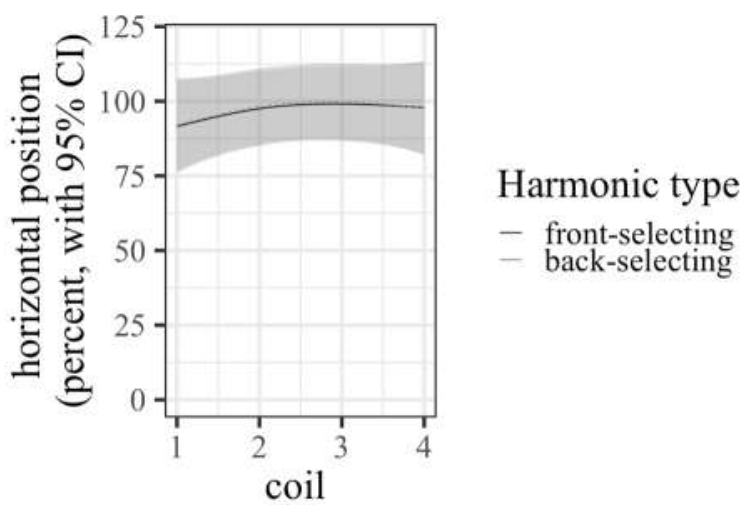

(1 - ttip, 2 - tbl, 3 - tbo1, 4 - tbo2)

Figure 2: Normalised horizontal positions of the coils as a function of harmonic type. 


\subsection{Words in sentence-initial position (sentence setup)}

Sentence-initially, target words were followed by (i) only front vowels (éppen /e:p:en/) or (ii) only back vowels (ugyan /ujpn/). We expected that due to the regressive $\mathrm{V}$-to- $\mathrm{V}$ coarticulation effects, front-selecting and back-selecting stems exhibit different patterns in the various contexts in terms of tongue position. As Fig. 3 shows, systematic differences in receiver coil positions were not found with the exception of the word sziv in the éppen context, where the positions appeared to be systematically divergent. However, the statistical analyses did not show differences neither as the function of harmonic type nor as the function of the target word.

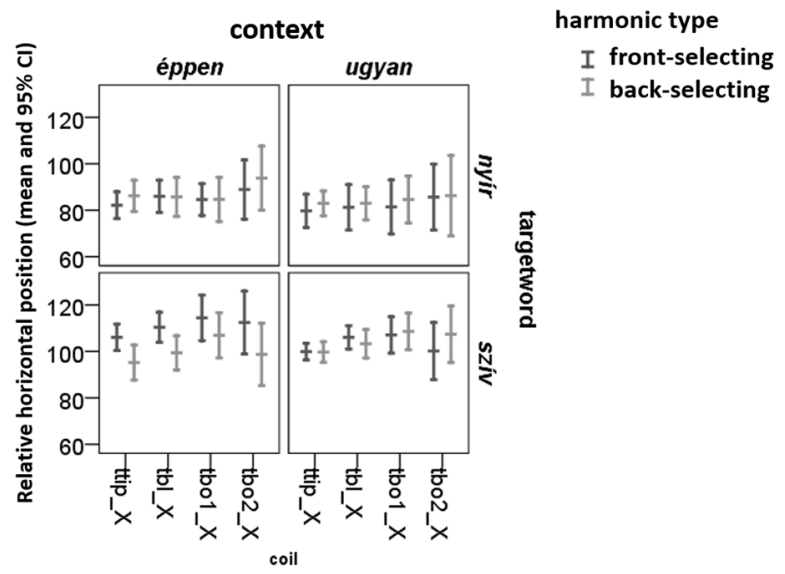

Figure 3: Relative horizontal coil positions (mean and $95 \%$ CI) as a function of target word, harmonic type and context.

The front/back quality of the context apparently had an effect on the vowel of the target words (Fig.4), but this effect did not show harmonic type dependent characteristics. The model not including by-condition smooths had a lower AIC than the model containing those, both for the model not containing (AIC difference $=13.312$ ) and containing the additional interaction with target word (AIC difference $=11.450)$.

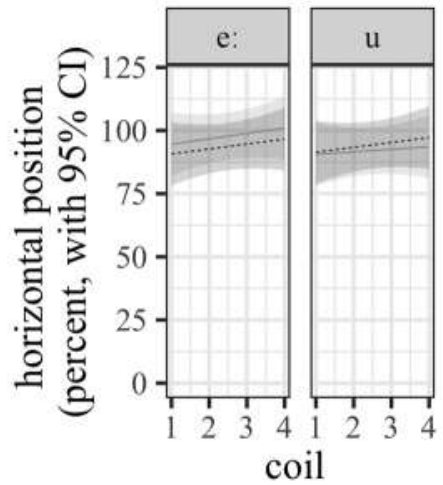

\section{Harmonic type}

- front-selecting

(1 - ttip, 2 - tbl, 3 - tbo1, 4 - tbo2)

Figure 4: Normalised horizontal positions of the coils as a function of harmonic type and context.

\section{Discussion and conclusions}

In the present study, the articulatory characteristics of the transparent vowel /ii/ were analysed in monosyllabic homophonous word pairs of Hungarian. One member of the word pairs was front-selecting (harmonic) according to its harmonic behavior, while the other member was a backselecting (antiharmonic) stem. Two experimental setups were compiled and tested with electromagnetic articulometry.

In the first setup, the words occurred in isolation (no suffix, no carrier sentence), and pictures helped the speakers with the disambiguation of the meaning. We expected that similarly to the findings of [1], the transparent vowel would be pronounced with more fronted tongue position in the front-selecting (harmonic) stems compared to the back-selecting (antiharmonic) stems (irrespective of the presence of the suffix). This hypothesis was not corroborated as statistical analysis did not show significant difference between the frontand back-selecting homophonous words in terms of the receiver coil positon.

In the second setup, the words occurred sentence-initially, and were followed by (i) front or (ii) back vowels (although the meaning was clear from the contexts, pictures were also used in order to provide a congruent situation). Assuming that tongue position indeed differentiates between the front- and backselecting homophonous stems' vowels, we expected that the effect of regressive $\mathrm{V}$-to- $\mathrm{V}$ coarticulation would be different as a function of the harmonic type of the stem. However, this hypothesis was not corroborated, either.

While the monosyllabic word set used by [1] contained some questionable pairs in which the front- and back-selecting stems were not in agreement in their syllable structures or the place of articulation of the consonants surrounding the vowel, in our experiment two pairs of homophonous monosyllabic stems were applied. Apparently, the context had an effect on the results of [1], as it was also observed in the comparison of our two words: sziv and nyir. Therefore, the conclusions formulated by [1] on the sub-phonemic differences between the realizations of transparent vowels in front- and back-selecting stems are to be handled with care. Based on our data obtained with a wellcontrolled material, it might be concluded that sub-phonemic differences (if they exist) cannot be traced back to (different) tongue positions associated with the transparent vowels' realizations in front- (harmonic) and back-selecting (antiharmonic) stems. Further studies with more speakers might make the picture more clear, and could provide more details on this issue.

\section{Acknowledgements}

The authors are grateful to Ákos Buza, Valéria Krepsz, István Mrázik, Zsófia Puzder, and Zsófia Weidl for their help with conducting the experiments and analysing the data.

\section{References}

[1] S. Benus and A. Gafos, "Articulatory characteristics of Hungarian 'transparent' vowels," Journal of Phonetics, vol. 35, pp. 271-300, 2007.

[2] B. Hayes, K. Zuraw, P. Siptár, and Zs. Londe, "Natural and unnatural constraints in Hungarian vowel harmony," Language, vol. 85, no. 4, pp. 822-863, 2009.

[3] P. Siptár, and M. Törkenczy, The Phonology of Hungarian. New York: Oxford University Press, 2007. 
[4] U. Reichel, "PermA and Balloon: Tools for string alignment and text processing." paper no. 346, 2012.

[5] F. Schiel, "Automatic phonetic transcription of nonprompted speech," Proceedings of the International Congress of Phonetic Sciences, pp. 607-610, 1999.

[6] P. Boersma and D. Weenink, Praat: doing phonetics by computer [Computer program]. Version 6.0.43, http://www.praat.org/, 2018.

[7] T. Cho, "Prosodically conditioned strengthening and vowel-tovowel coarticulation in English," Journal of Phonetics, vol. 32, pp. 141-176, 2004

[8] R Core Team, R: A Language and Environment of Statistical Computing, $\mathrm{R}$ Foundation for Computing, Vienna, https://www.R-project.org, 2018.

[9] S. N. Wood, "mgcv: GAMs and generalized ridge regression for R," $R$ news, vol. 1, no.2, pp. 20-25, 2001.

[10] H. Akaike, "A new look at the statistical model identification," IEEE Transactions on Automatic Control, vol. 19, no. 6, pp. 716$723,1974$.

[11] J. van Rij, M. Wieling, R. Baayen, H. van Rijn, itsadug: Interpreting Time Series and Autocorrelated Data Using GAMMs, R package version 2.3. 2017.

[12] S. Coretta, tidymv: Tidy Model Visualisation. $R$ package version 1.5.4.9000. https://github.com/stefanocoretta/tidymv, 2018. 